\title{
Quality of life following glaucoma surgery: canaloplasty versus trabeculectomy
}

\author{
This article was published in the following Dove Press journal: \\ Clinical Ophthalmology \\ 18 December 2014 \\ Number of times this article has been viewed
}

\author{
Thomas Klink' \\ Johannes Sauer' \\ Norbert J Körber ${ }^{2}$ \\ Franz Grehn' \\ Martin M Much' \\ Luisa Thederan' \\ Juliane Matlach' \\ Josefina Parente Salgado' \\ 'Department of Ophthalmology, \\ University of Würzburg, Würzburg, \\ Germany; ${ }^{2}$ Augencentrum Köln-Porz, \\ Köln, Germany
}

Purpose: To evaluate quality of life (QoL) with a new questionnaire after canaloplasty (CP) and trabeculectomy (TE).

Patients and methods: We assessed outcomes of surgery, rate of revision surgeries, patients' mood, and influence of postoperative care on QoL, surgery interference with daily activities, and postsurgical complaints. Patients completed the QoL questionnaire 24 months after surgery.

Results: Patients who underwent CP $(n=175)$ were compared to TE patients $(n=152)$. In the $\mathrm{CP}$ group, $57 \%$ of patients expressed high satisfaction, while $41 \%$ of patients in the TE group said they were highly satisfied. The satisfaction difference was statistically significant $(P=0.034)$. Significantly fewer second surgeries were needed after $\mathrm{CP}(8 \% \mathrm{CP}$ versus $35 \% \mathrm{TE}$, $P<0.001$ ). Patients were more positive in the CP group (54\% CP versus $37 \%$ TE, $P<0.009$ ). Stress related to postoperative care was lower in the CP group compared to the TE group (14\% versus $46 \%$ ). Difficulties with activities of daily living, such as reading, were much lower or even nonexistent after $\mathrm{CP}$, and complaints like eye burning or stinging were significantly lower in the $\mathrm{CP}$ group.

Conclusions: Compared with TE, CP is associated with less QoL impairment and higher patient satisfaction after surgery. However, long-term data on intraocular pressure reduction after surgery are needed to confirm long-term patient satisfaction with this surgery.

Keywords: glaucoma, postoperative care, glaucoma surgery, non-penetrating glaucoma surgery

\section{Introduction}

According to the guidelines of the European Glaucoma Society, "the goal of glaucoma treatment is to maintain the patient's visual function and related quality of life (QoL), at a sustainable cost." In medically uncontrolled chronic open angle glaucoma, the gold standard for reducing intraocular pressure is trabeculectomy (TE), a type of penetrating glaucoma surgery. Unfortunately, this is associated with severe intraoperative and postoperative complications, such as overfiltration with hypotony and further complications like wound leak, bleb scarring, revision surgery, and blebitis. ${ }^{2}$

A newer surgical procedure avoiding severe bleb-related complications is canaloplasty (CP), a nonpenetrating surgical method. The aims of this surgery are to restore the natural outflow pathways and to achieve blebless intraocular pressure control. ${ }^{3}$ The rate of complications is lower than with TE, ${ }^{4}$ but CP comprises surgery-specific complications such as detachment of Descemet's membrane. ${ }^{5}$

Assessment of QoL and patient satisfaction is becoming increasingly important in the decision-making process regarding the choice of a therapeutic procedure. There are currently several ways to measure QoL. Some are very general in nature. Others have been developed specifically for ophthalmologic use (eg, the Visual Function Index ${ }^{6}$ ). With regard to glaucoma, there are some established questionnaires, eg, the Glaucoma
Correspondence: Thomas Klink Department of Ophthalmology, University of Würzburg, Josef-SchneiderStr II, D-97080 Würzburg, Germany $\mathrm{Tel}+49$ 93I 2010

Fax +4993120120490

Email klink_t@ukw.de 
Quality of Life-15 Items or the Glaucoma Symptom Scale, ${ }^{7,8}$ but none address glaucoma surgery-related issues.

The aims of this study were to evaluate QoL and patient satisfaction after glaucoma surgery and to determine whether there were any differences between CP and TE. A new QoL questionnaire was developed specifically for this study.

\section{Materials and methods}

\section{Patients}

For this cross-sectional retrospective study, we consecutively selected patients with primary open angle glaucoma undergoing either trabeculectomy with mitomycin $\mathrm{C}$ or canaloplasty between 2008 and 2010. Phacotrabeculectomy and phacocanaloplasty was performed in $20.4 \%$ (31 of 121 trabeculectomy patients) and 35.8\% (63 of 113 canaloplasty patients), respectively. The surgeries were carried out by one of three surgeons: NK, FG, or TK. The study was approved by University of Würzburg's institutional review board, and all patients provided written informed consent.

\section{QoL questionnaire}

In order to assess the influence of surgery on daily activities, postoperative complaints, subjective outcomes of surgery, rate of revision surgeries, patients' postoperative mood, and the influence of postoperative care on QoL, a questionnaire with different subscales was developed. We have used the following existing and established questionnaires ${ }^{8-16}$ : Glaucoma Symptom Scale, Visual Activities Questionnaire, Impact of Vision Impairment, National Eye Institute-Visual Functioning Questionnaire, National Eye Institute-Visual Functioning Questionnaire-25 items, Glaucoma Health Perception Index, Glaucoma Quality of Life-15 items, Activities of Daily Vision Scale, and Visual Function Questionnaire-14 items. Additionally, surgery-specific questions developed by expert consensus (three glaucoma surgeons: NK, FG, and TK) were included. The QoL questionnaire (Supplementary material) was mailed to the patients 24 months after surgery. The aim of the QoL measures was to assess patients' perceptions of their visual function, visually related complaints, nonvisual ophthalmic complaints, and overall topics related to surgery and daily life. The questionnaire included 21 items that are listed in Table 1.

The first 13 items and items 15, 16, and 20 of Table 1 were scored on a five-level scale to report how surgery had interfered with the different activities and emotions. Scores were assigned as follows: $5=$ not at all, $4=$ slightly, $3=$ partially, $2=$ predominantly, and $1=$ extremely. A score of 0 was assigned if the patient was not able to rate the activity.
For item 14, patients could select two terms from a list of words associated with a negative meaning (eg, frustrated, helpless), a neutral meaning (eg, uncertain) or a positive meaning (eg, happy, carefree). Items 17 and 18 were scored on a three-level scale: $1=$ more, 2 = equal, or $3=$ less. Item 19 asked about the number of revision surgeries a patient required after the initial procedure. Patients were given ordinal options: zero, once, twice, three times, four times, or more than four times. Item 21 had ten levels, from $0=$ totally discontent up to $10=$ totally content.

\section{Statistical analysis}

The data were analyzed with SPSS statistical software (version 16.0; SPSS Inc., Chicago, IL, USA). To compare the two treatment groups, Student's $t$-test and Pearson's chisquare test were performed after averaging the scores. Where appropriate, values are given as means \pm standard deviation. Statistical significance was considered to be $P \leq 0.05$.

\section{Results}

The questionnaire was sent to 423 patients (212 CP and 211 TE patients). A total of 327 patients returned the completed questionnaire (return rate of $75.8 \%$ ). Of the 327 questionnaires, 175 were completed by CP patients and 152 by TE patients. This represents a balanced evaluation result, with $53.7 \%$ and $46.3 \%$ questionnaires being completed by $\mathrm{CP}$ and TE patients, respectively. Patients were aged $18-90$ years ( $46.6 \%$ men, $53.4 \%$ women), with the 175 patients in the CP group consisting of 91 men and 84 women (aged 69.5 \pm 10.2 years) and the 152 patients in the TE with mitomycin $\mathrm{C}$ group consisting of 62 men and 90 women (aged 66.7 \pm 11.8 years).

Overall, canaloplasty patients had a higher QoL regarding positive postoperative mood, satisfaction with results of surgery, and lower rates of visual and nonvisual symptoms and stress caused by surgery or postsurgical treatment. No difference between trabeculectomy and canaloplasty was seen for restriction from social contacts and loss of independence.

The evaluation of visual ocular symptoms, such as change in visual acuity, reading newspapers, watching television, seeing in the dark, and driving were all significantly different in the two groups and were rated better in the canaloplasty group. Surgery interference with daily activities, eg, impairment in reading, was rated as much lower to nonexistent in the CP group (Figure 1). Likewise, there were differences in the nonvisual ocular symptoms, with significantly lower ratings of glare, burning and stinging of the eye, foreign body sensation, tearing, redness, and dryness in the CP group 
Table I Questionnaire items

\begin{tabular}{|c|c|c|}
\hline Item description & Questionnaire & Subscale \\
\hline I. Change in visual acuity & & Visual ocular symptoms \\
\hline 2. Reading newspapers & NEI-VFQ-25, VF-I4, VAQ, IVI, NEI-VFQ, GQL-I5, ADVS & \\
\hline 3. Watching television & NEI-VFQ-25, VF-I4, IVI, NEI-VFQ, GQL-I5, ADVS & \\
\hline 4. Seeing at night & NEI-VFQ-25, VF-I4, GSS, VAQ, GQL-I5, ADVS & \\
\hline 5. Driving & NEI-VFQ-25, VF-14, VAQ, NEI-VFQ, ADVS & \\
\hline 6. Glare & GSS, VAQ, GQL-I5, ADVS & Nonvisual ocular symptoms \\
\hline 7. Burning and stinging of the eye & NEI-VFQ-25, GSS, NEI-VFQ & \\
\hline 8. Foreign body sensation & GSS & \\
\hline 9. Tearing & GSS & \\
\hline \multicolumn{3}{|l|}{ 10. Redness } \\
\hline II. Dryness & GSS & \\
\hline $\begin{array}{l}\text { 12. Restriction of social contacts (attending social functions, } \\
\text { meeting with friends) }\end{array}$ & VFQ25, IVI, NEI-VFQ, GHPI, GQL-I5 & Self-care and social life \\
\hline $\begin{array}{l}\text { 13. Loss of independence (less control over own body, } \\
\text { being a burden on others, loss of confidence in doing } \\
\text { usual activities) }\end{array}$ & NEI-VFQ-25, IVI, NEI-VFQ, GQL-I5, ADVS & \\
\hline 14. Postoperative mood & & Emotional symptoms \\
\hline \multicolumn{3}{|l|}{ 15. Stress caused by surgery } \\
\hline \multicolumn{3}{|l|}{ 16. Stress caused by postoperative care } \\
\hline 17. Difference in number of eye drops before/after surgery & & Results of surgery \\
\hline \multicolumn{3}{|l|}{ 18. Difference in number of follow-ups before/after surgery } \\
\hline \multicolumn{3}{|l|}{ 19. Number of revision surgeries } \\
\hline 20. Fulfilling of expectations not to use drops anymore & & Patient satisfaction \\
\hline \multicolumn{3}{|l|}{ 21. Satisfaction with results of surgery } \\
\hline $\begin{array}{l}\text { Notes: Items I-13, I5, 16, and } 20 \text { were scored on a five-level scale: } 5 \\
\text { two terms from a list of words associated with a negative meaning (eg } \\
\text { Items } 17 \text { and } 18 \text { were scored on a three-level scale: I = more, } 2 \text { = equ } \\
\text { three times, four times or more than four times. Item } 21 \text { had ten levels } \\
\text { Abbreviations: ADVS, Activities of Daily Vision Scale; GHPI, Glauc } \\
\text { Symptom Scale; IVI, Impact of Vision Impairment; NEI-VFQ, National } \\
\text { Functioning Questionnaire-25 items; VAQ, Visual Activities Questionn }\end{array}$ & $\begin{array}{l}\text { not at all, } 4=\text { slightly, } 3=\text { partially, } 2=\text { predominantly, I = extrem } \\
\text { rustrated, helpless), a neutral meaning (eg, uncertain), or a posit } \\
\text {, or } 3=\text { less. Item I9: Number of revision surgeries after the ini } \\
\text { rom } 0=\text { totally discontent up to } 10=\text { totally content. } \\
\text { ma Health Perception Index; GQL- I5, The Glaucoma Quality } \\
\text { e Institute-Visual Functioning Questionnaire; NEI-NEI-NEI-VFQ }\end{array}$ & $\begin{array}{l}\text { ely, } 0=\text { not rated. Item I4: Select } \\
\text { ive meaning (eg, happy, carefree). } \\
\text { tial procedure (zero, once, twice, } \\
\text { of Life-I5 items; GSS, Glaucoma } \\
-25, \text { National Eye Institute-Visual }\end{array}$ \\
\hline
\end{tabular}

compared with the TE group (Figure 2). Further significant differences were observed in patients' mood (positive mood: $54 \%$ in the CP group versus $37 \%$ in the TE group, $P=0.009$ ) and the stress caused by surgery, with patients in the $\mathrm{CP}$ group being happier and less stressed about the surgery ( $84 \%$ versus $51 \%$ in the TE group, $P<0.001$ ). The stress induced by the postsurgical care was also significantly lower after CP (14\% versus $46 \%$ in the TE group, $P<0.001)$. In contrast, the differences in the number of follow-ups before and after surgery were comparable between the groups. Fifty-seven percent of the patients undergoing CP were highly satisfied with the results of surgery; in the TE group, this rate was $41 \%$. Interestingly, the other side of the scale, which depicted patients who were not at all satisfied with the surgery, revealed $6 \%$ in the $\mathrm{CP}$ group and $3 \%$ in TE group. The significant differences in patient satisfaction are shown in Figure 3 (mean \pm standard deviation $=8.09 \pm 2.71$ in the $\mathrm{CP}$ group and 7.46 \pm 2.61 in the TE group; $P=0.034)$. The rate of revision surgeries was significantly lower after CP $(8 \%$ versus $35 \%$ after TE; $P<0.001)$.
Social functions, such as the restriction from social contacts, did not show significant differences between groups $(P=0.766)$. The two treatment groups were also comparable for the perception of loss of independence $(P=0.875)$, the expectation not to use drops anymore $(P=0.631)$, and

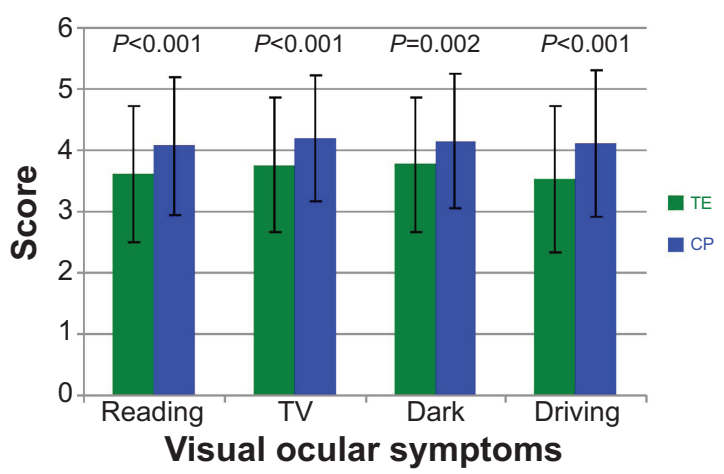

Figure I Quality-of-life-questionnaire: visual ocular symptoms.

Notes: Change in reading, watching TV, driving, and seeing at night were scored on a five-level scale: 5 = not at all, 4 = slightly, 3 = partially, 2 = predominantly, I = extremely, $0=$ not rated. A higher score defines few to no visual symptoms. Values are means and error bars indicate the standard deviation.

Abbreviations: CP, canaloplasty; TE, trabeculectomy; TV, television. 


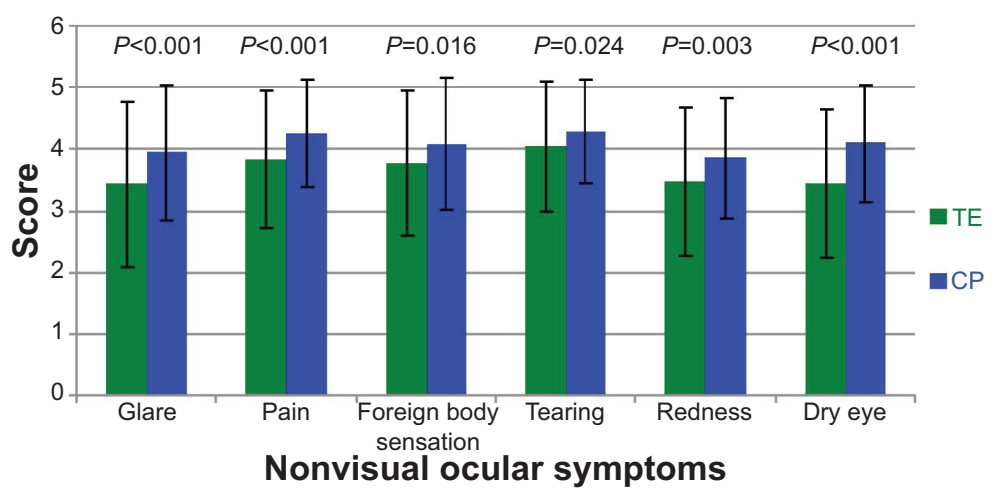

Figure 2 Quality-of-life-questionnaire: nonvisual ocular symptoms.

Notes: Glare, burning and stinging of the eye, foreign body sensation, dryness of the eye, and redness of the eye were scored on a five-level scale: $5=$ not at all, $4=$ slightly, $3=$ partially, 2 = predominantly, 1 = extremely, $0=$ not rated. A higher score defines few to no nonvisual symptoms. Values are means and error bars indicate the standard deviation.

Abbreviations: CP, canaloplasty; TE, trabeculectomy.

the difference in number of eye drops before and after surgery.

The full results are summarized in Table 2.

\section{Discussion}

The goals of glaucoma surgery are not only to reduce intraocular pressure, but also especially to maintain visual fields and visual acuity, preserving the patient's QoL and independence. It also aims to improve QoL, for example, by reducing the interference from the disease with daily life and by decreasing ophthalmic therapy along with associated ocular and systemic side effects and complications.

There are a few published studies evaluating QoL in glaucoma, ${ }^{8-16}$ but none have compared CP with TE. This study evaluated the QoL of patients after glaucoma surgery.

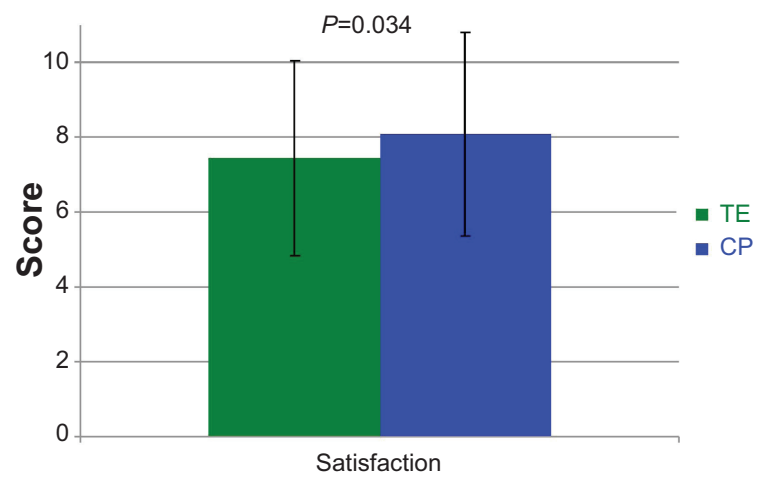

Satisfaction with surgery

Figure 3 Quality-of-life-questionnaire: patient satisfaction with the results of surgery. Notes: Satisfaction with the surgery was scored from $0=$ totally discontent up to $10=$ totally content. A higher score defines a better overall satisfaction with the results of the surgery. Values are means and error bars indicate the standard deviation.

Abbreviations: CP, canaloplasty; TE, trabeculectomy.
Visually-related criteria were used, as found in the Glaucoma Quality of Life-15 items questionnaire. ${ }^{14}$ A significant difference was found in central vision activities, with $\mathrm{CP}$ showing less interference with those than TE. This might be explained by the postoperative complications of TE, such as hypotony, which are associated with a reduction in central vision. Nonvisual ocular symptoms were also considered, as in the Glaucoma Symptom Scale. ${ }^{8}$ Likewise, we found a significant difference between the $\mathrm{CP}$ and TE groups in the subscale of nonvisual symptoms, with better QoL in the $\mathrm{CP}$ group. The nonvisual ocular symptoms expressed mostly by patients in the TE group are probably related to the postoperative subconjunctival use of antiproliferative substances, such as 5-fluorouracil.

Follow-up visits and postoperative treatments are more common and extensive after TE, which might cause more discontent and stress. In this study, the stress caused by surgery, as well as by treatments and follow-up visits, was significantly higher in the TE group, a finding that is supported by a lower satisfaction rating in this group (41\% highly satisfied after TE versus $57 \%$ after CP). Surprisingly, the analysis of the number of follow-ups before and after surgery revealed no significant difference between the two groups: $14.5 \%$ of patients in the TE group had to visit the ophthalmologist more often, compared with $7.5 \%$ in the CP group. This is in agreement with the data published by Taube et $a 1^{18}$ regarding the number of postoperative visits and bleb revisions after TE.

A study by Ayyala et $a l^{4}$ showed no statistical difference when comparing the number of revision surgeries with $\mathrm{CP}$ and TE. In our cohort, the number of revision surgeries was significantly higher in the TE group. This result supports the known higher complication rate of TE and the greater need 
Table 2 Quality of life outcomes

\begin{tabular}{|c|c|c|c|c|c|}
\hline & \multicolumn{2}{|c|}{ Canaloplasty } & \multicolumn{2}{|c|}{ Trabeculectomy } & \multirow[t]{2}{*}{$P$-value* } \\
\hline & $\mathbf{n}$ & Mean \pm SD & $\mathbf{n}$ & Mean \pm SD & \\
\hline Change in visual acuity & 110 & $3.29 \pm 0.82$ & 112 & $2.83 \pm 0.94$ & 0.001 \\
\hline Reading newspapers & 108 & $4.27 \pm 1.08$ & 118 & $3.65 \pm 1.15$ & $<0.001$ \\
\hline Watching television & 109 & $4.37 \pm 0.92$ & 117 & $3.79 \pm 1.11$ & $<0.001$ \\
\hline Seeing at night & 108 & $4.31 \pm 0.98$ & 119 & $3.82 \pm 1.10$ & $<0.001$ \\
\hline Driving & 94 & $4.28 \pm 1.06$ & 96 & $3.56 \pm 1.20$ & $<0.001$ \\
\hline Glare & 110 & $4.02 \pm 1.09$ & 120 & $3.36 \pm|.3|$ & $<0.001$ \\
\hline Pain & 112 & $4.33 \pm 0.84$ & 118 & $3.86 \pm 1.15$ & $<0.001$ \\
\hline Foreign body sensation & 176 & $4.08 \pm 1.08$ & 152 & $3.78 \pm 1.18$ & 0.016 \\
\hline Tearing & 176 & $4.28 \pm 0.85$ & 152 & $4.04 \pm 1.05$ & 0.024 \\
\hline Redness & 171 & $3.85 \pm 0.98$ & 150 & $3.47 \pm 1.21$ & 0.003 \\
\hline Dry eye & 170 & $4.09 \pm 0.95$ & 151 & $3.44 \pm 1.20$ & $<0.001$ \\
\hline Fulfillment of expectations not to use drops anymore & 113 & $4.09 \pm 1.36$ & 116 & $4.00 \pm 1.43$ & 0.6 \\
\hline Stress caused by surgery & 175 & $4.18 \pm 0.86$ & 149 & $3.59 \pm 1.12$ & $<0.001$ \\
\hline Stress caused by follow-ups/treatments & 176 & $4.36 \pm 0.80$ & 151 & $3.40 \pm 1.20$ & $<0.001$ \\
\hline Difference in number of eye drops before/after surgery & 113 & $2.76 \pm 0.51$ & 118 & $2.73 \pm 0.56$ & 0.7 \\
\hline Difference in number of follow-ups before/after surgery & 174 & $4.36 \pm 0.80$ & 151 & $3.40 \pm 1.20$ & 0.2 \\
\hline Revision surgeries & 176 & $0.12 \pm 0.43$ & 150 & $0.67 \pm 1.14$ & $<0.001$ \\
\hline Postoperative mood & 176 & $2.30 \pm 0.83$ & $|5|$ & $1.96 \pm 0.87$ & 0.009 \\
\hline Satisfaction with results of surgery & 175 & $8.09 \pm 2.71$ & 152 & $7.46 \pm 2.61$ & 0.034 \\
\hline Restriction of social contacts & 110 & $4.54 \pm 0.99$ & 115 & $4.57 \pm 0.90$ & 0.8 \\
\hline Loss of independence & 112 & $4.45 \pm 0.88$ & 121 & $4.45 \pm 0.88$ & 0.9 \\
\hline
\end{tabular}

Notes: *Student's t-test, Pearson's chi-square test as appropriate.

Abbreviations: $n$, number of answers; SD, standard deviation.

for revision surgeries in penetrating glaucoma surgery, as well as the findings of Lewis et $\mathrm{al}^{5}$ with a rare re-intervention after CP.

Activities of daily living and psychological aspects (individual experiences, emotions, and behavior), as used in the Glau-QoL 36-item questionnaire ${ }^{17}$ and in Jampel's Glaucoma Health Perception Indices, ${ }^{19}$ were also evaluated. There were no significant differences between the CP and TE groups for restriction of social contacts, self-esteem, or loss of independence. However, the postoperative mood was significantly better in the $\mathrm{CP}$ group, which may be related to a less-intensive need for postoperative care and revision procedures.

Overall, our study showed good results for maintenance of QoL after glaucoma surgery, with patients expressing high satisfaction with the outcomes of surgery both after CP and TE. A slight superiority of CP was noted, with a significantly higher satisfaction rate in the CP group. On the other hand, it should be pointed out that the percentage of completely unsatisfied patients was greater in the $\mathrm{CP}$ group than in the TE group. This fact may be related to greater expectations or to insufficient intraocular pressure reduction in this group.

Limitations of our study are its retrospective design, a common source of bias and confounding. We have focused only on QoL assessment following canaloplasty or trabeculectomy. Therefore, patients were not compared regarding severity of glaucoma, including preoperative intraocular pressure, visual acuity, number of medications, and previous ocular surgeries. Prospective long-term studies with a greater sample size and patients with comparable preoperative characteristics are needed to confirm these results.

In summary, our findings indicate that $\mathrm{CP}$ is associated with an overall lower impairment of QoL after surgery and with higher patient satisfaction than TE. Long-term data on intraocular pressure reduction after surgery are needed to confirm long-term patient satisfaction and cost efficiency with this new type of nonpenetrating surgery.

\section{Acknowledgment}

We would like to thank Dipl Math Johannes Hain for his counselling in the statistical analysis.

\section{Disclosure}

The authors report no conflicts of interest in this work. Results were presented at the 10th EGS (European Glaucoma Society) Congress, June 17-22, 2012 in Copenhagen. 


\section{References}

1. European Glaucoma Society. Terminology and Guidelines for Glaucoma. 3rd ed. Savona, Italy: Editrice Dogma S.r.1.; 2008.

2. Razeghinejad MR, Fudemberg SJ, Spaeth GL. The changing conceptual basis of trabeculectomy: a review of past and current surgical techniques. Surv Ophthalmol. 2012;57(1):1-25.

3. Niegel M, Körber N. [Non-penetrating glaucoma surgery]. Klin Monbl Augenheilkd. 2012;229(4):471-80; quiz 481. German.

4. Ayyala RS, Chaudhry AL, Okogbaa CB, Zurakowski D. Comparison of surgical outcomes between canaloplasty and trabeculectomy at 12 months' follow-up. Ophthalmology. 2011;118(12):2427-2433.

5. Lewis RA, von Wolff K, Tetz M, et al. Canaloplasty: Three-year results of circumferential viscodilation and tensioning of Schlemm canal using a microcatheter to treat open-angle glaucoma. J Cataract Refract Surg. 2011;37(4):682-690.

6. Stein JD. Disparities between ophthalmologists and their patients in estimating quality of life. Curr Opin Ophthalmol. 2004;15(3):238-243.

7. Goldberg I, Clement CI, Chiang TH, et al. Assessing quality of life in patients with glaucoma using the Glaucoma Quality of Life-15 (GQL-15) questionnaire. J Glaucoma. 2009;18(1):6-12.

8. Lee BL, Gutierrez P, Gordon M, et al. The Glaucoma Symptom Scale. A brief index of glaucoma-specific symptoms. Arch Ophthalmol. 1998;116(7):861-866.

9. Sloane ME, Ball K, Owsley C, Bruni JR, Roenker DL. The Visual Activities Questionnaire: developing an instrument for assessing problems in everyday visual tasks. Technical Digest, Noninvasive Assessment of the Visual System Topical Meeting of the Optical Society of America; 1992 Jan 7-31; Salt Lake City, UT. Washington, DC: Optical Society of America, 1992.

10. Weih LM, Hassell JB, Keeffe J. Assessment of the impact of vision impairment. Invest Ophthalmol Vis Sci. 2002;43(4):927-935.
11. Mangione CM, Lee PP, Pitts J, Gutierrez P, Berry S, Hays RD. Psychometric properties of the National Eye Institute visual function questionnaire (NEI-VFQ). NEI-VFQ Field Test Investigators. Arch Ophthalmol. 1998;116(11):1496-1504.

12. Mangione CM, Lee PP, Gutierrez PR, Spritzer K, Berry S, Hays RD; National Eye Institute Visual Function Questionnaire Field Test Investigators. Development of the 25-list-item National Eye Institute Visual Function Questionnaire. Arch Ophthalmol. 2001;119(7): 1050-1058.

13. Janz NK, Wren PA, Lichter PR, Musch DC, Gillespie BW, Guire KE. Quality of life in newly diagnosed glaucoma patients: The Collaborative Initial Glaucoma Treatment Study. Ophthalmology. 2001;108(5):887-897.

14. Nelson P, Aspinall P, Papasouliotis O, Worton B, O'Brien C. Quality of life in glaucoma and its relationship with visual function. J Glaucoma. 2003;12(2):139-150.

15. Mangione CM, Phillips RS, Seddon JM, et al. Development of the 'Activities of Daily Vision Scale'. A measure of visual functional status. Med Care. 1992;30(12):1111-1126.

16. Steinberg EP, Tielsch JM, Schein OD, et al. The VF-14. An index of functional impairment in patients with cataract. Arch Ophthalmol. 1994;112(5):630-638.

17. Béchetoille A, Arnould B, Bron A, et al. Measurement of health-related quality of life with glaucoma: validation of the Glau-QoL 36-item questionnaire. Acta Ophthalmol. 2008;86(1):71-80.

18. Taube AB, Niemelä $\mathrm{P}, \mathrm{Alm} \mathrm{A}$. Trabeculectomy with an active postoperative regimen: results and resource utilization. Acta Ophthalmol. 2009;87(5):524-528.

19. Jampel HD, Frick KD, Janz NK, et al; CIGTS Study Group. Depression and mood indicators in newly diagnosed glaucoma patients. Am J Ophthalmol. 2007;144(2):238-244. 


\section{Supplementary material}

\section{Quality of life questionnaire: trabeculectomy versus canaloplasty}

Question 1: Have you had a combined cataract and glaucoma surgery (trabeculectomy or canaloplasty)?

O Yes

O No

Question 2: Has your vision changed after surgery?

Onot at all (5)

O slightly (4)

O partially (3)

$\bigcirc$ predominantly (2)

$\bigcirc$ extremely (1)

O not rated (0)

Question 3: How long did you stay in the hospital after surgery?
outpatient (6)
up to 3 days (5)
$\bigcirc$ up to 5 days (4)
up to 7 days (3)
up to 14 days (2)
more than 14 days (1)

Question 4: How has the surgery influenced the following daily activities?

4.1 Reading a newspaper/book

O not at all (5)

O slightly (4)

partially (3)

$\bigcirc$ predominantly (2)

$\bigcirc$ extremely (1)

not rated (0)

4.2 Watching TV

O not at all (5)

O slightly (4)

partially (3)

$\bigcirc$ predominantly (2)

$\bigcirc$ extremely (1)

O not rated (0)

4.3 Seeing at night

$O$ not at all (5)

O slightly (4)

O partially (3)

$\bigcirc$ predominantly (2)

$\bigcirc$ extremely (1)

$\bigcirc$ not rated (0)

4.4 Driving

O not at all (5)

O slightly (4)

O partially (3)

$\bigcirc$ predominantly (2)

$\bigcirc$ extremely (1)

not rated (0) 
Question 5: Have you suffered from glare after surgery?

O not at all (5)

slightly (4)

partially (3)

$\bigcirc$ predominantly (2)

O extremely (1)

$\bigcirc$ not rated $(0)$

Question 6: Have you suffered from burning and stinging of the eye after surgery?

O not at all (5)

O slightly (4)

O partially (3)

predominantly (2)

O extremely (1)

Onot rated (0)

Question 7: Have you suffered from a foreign body sensation after surgery?

O not at all (5)

O slightly (4)

$\bigcirc$ partially (3)

$\bigcirc$ predominantly (2)

$\mathrm{O}$ extremely (1)

O not rated (0)

Question 8: Have you suffered from tearing after surgery?

$\mathrm{O}$ not at all (5)

O slightly (4)

$\bigcirc$ partially (3)

$\bigcirc$ predominantly (2)

$\bigcirc$ extremely (1)

$\bigcirc$ not rated $(0)$

Question 9: Have you suffered from a red eye after surgery?

O not at all (5)

O slightly (4)

$\bigcirc$ partially (3)

$\bigcirc$ predominantly (2)

O extremely (1)

$\bigcirc$ not rated (0)

Question 10: Have you suffered from a dry eye after surgery?

O not at all (5)

o slightly (4)

O partially (3)

$\bigcirc$ predominantly (2)

$\bigcirc$ extremely (1)

not rated (0)

Question 11: How were your expectation fulfilled not to use eye drops after surgery?

O not at all (5)

O slightly (4)

O partially (3)

$\bigcirc$ predominantly (2)

$\bigcirc$ extremely (1)

$\bigcirc$ not rated (0) 
Question 12: Do you take

O more (1)

O same (2)

O less (3)

eye drops after surgery?

Question 13: How stressful was the surgery for you?

O not at all (5)

O slightly (4)

O partially (3)

$\bigcirc$ predominantly (2)

$\bigcirc$ extremely (1)

not rated (0)

Question 14: How stressful were the follow-up appointments and treatments after surgery?

O not at all (5)

O slightly (4)

p partially (3)

$\bigcirc$ predominantly (2)

O extremely (1)

not rated (0)

Question 15: Have you had a second, third etc. surgery after the initial trabeculectomy or canaloplasty? If yes, how many

O No (6)

$\mathrm{O}$ one (5)

O two (4)

O three (3)

$\bigcirc$ four (2)

O more than four (1)

Question 16: Has your social life (eg, going out with friends) changed after surgery?

O not at all (5)

O slightly (4)

partially (3)

$\bigcirc$ predominantly (2)

$\bigcirc$ extremely (1)

$O$ not rated (0)

Question 17: Were you less independent (less control over own body, being a burden on others, loss of confidence in doing usual activities) after surgery?

O not at all (5)

O slightly (4)

O partially (3)

$\bigcirc$ predominantly (2)

$\mathrm{O}$ extremely (1)

$\mathrm{O}$ not rated (0)

Question 18: Number of follow-up appointments after surgery

O less often (3)

O same (2)

more often (1)

than before surgery.

Question 19: How satisfied were you with the results of the surgery?

Scale $=0$ (totally discontent) to 10 (totally content 0 10 
Question 20: How is your mood after surgery? (not more than 2 words)

frustrated - annoyed - anxious - helpless - worried - doubtful

satisfied - happy - cheerful - worry-free - glad - confident

Question 21: How old are you?

When did you have the surgery (month/year)?

Are you

O female

O male

Thank you very much!

\section{Publish your work in this journal}

Clinical Ophthalmology is an international, peer-reviewed journal covering all subspecialties within ophthalmology. Key topics include: Optometry; Visual science; Pharmacology and drug therapy in eye diseases; Basic Sciences; Primary and Secondary eye care; Patient Safety and Quality of Care Improvements. This journal is indexed on
PubMed Central and CAS, and is the official journal of The Society of Clinical Ophthalmology (SCO). The manuscript management system is completely online and includes a very quick and fair peer-review system, which is all easy to use. Visit http://www.dovepress.com/ testimonials.php to read real quotes from published authors. 